\title{
ALGUNOS ANTECEDENTES DEL LIBERALISMO CONSTITUCIONAL EN ESPAÑA: EL PENSAMIENTO POLÍTICO DE LA SEGUNDA ESCOLÁSTICA
}

\author{
LEÓN GÓMEZ RIVAS
}

\begin{abstract}
Resumen: Tanto en lo referente a la teoría del contrato social, como a los fundamentos "democráticos» de la autoridad civil, las universidades españolas llevaban varios siglos enseñando unas doctrinas que luego pusieron de moda los teóricos del liberalismo (desde Locke hasta Rousseau); pero que, como sostendremos a continuación, ya habían sido expuestas desde la época de Vitoria y —sobre todo-Suárez, hasta las postrimerías del siglo XVIII. Y que resumidamente podemos expresar así: según las teorías escolásticas del pactum translationis, la autoridad civil recae directamente en el pueblo, quien la delega en el soberano. Al faltar éste, ese poder vuelve a la sociedad; que justamente sería la circunstancia histórica de 1808 con la invasión napoleónica de España y el surgimiento de unas Juntas a ambos lados del Atlántico, como garantes de la legitimidad gubernativa.
\end{abstract}

Palabras clave: Escolástica, liberalismo, Escuela de Salamanca, Cortes de Cádiz.

Códigos JEL: B 11 .

Abstract: The name «School of Salamanca» is refered to a group of theologians and Natural Law philosophers who taught in the University of Salamanca, following the inspiration of the great tomist Francisco de Vitoria. They developed some original theories on Political Thought, like the pactum translationis (or the delegated power to the kings from the civil society) and the right of resistance to tyranny. Theories that will revive at the times of the French invasion of Spain (1808-1812).

Procesos de Mercado: Revista Europea de Economía Política Vol. V, n. ${ }^{\circ}$ 2, Otoño 2008, pp. 175 a 197 
Key words: Scholastics, liberalism, School of Salamanca, 1812 Spanish Constitution.

JEL codes: B 11.

Quod omnes tangit, debet ab omnibus approbari ${ }^{1}$

Bonifacio VIII, Decretales (1298)

En el marco de las celebraciones de los doscientos años de nuestra Guerra de la Independencia, y que se completa con el Bicentenario de las Cortes de Cádiz, quiero ofrecer aquí una aportación relacionada con los posibles antecedentes escolásticos de este constitucionalismo liberal de comienzos del siglo XIX. Como trataremos de demostrar a continuación, el pensamiento tardoescolástico (formado durante los siglos XVI y XVII en las cátedras de la Universidad de Salamanca) pudo llegar a tener un papel de protagonismo en la gestación de las ideas que hicieron nacer unas «juntas de patriotas» opuestos al dominio francés en España, germen de las referidas Cortes de Cádiz.

$Y$ aunque es correcto hablar de una cultura universitaria ya decadente en la España del siglo XVIII, puede decirse con poca exageración que aquellas ideas precursoras se habrían adelantado un par de siglos a Adam Smith en la defensa del liberalismo económico; y cien años al liberalismo político de John Locke². Por lo que no es de extrañar que de alguna manera continuasen vigentes en el acervo cultural de la última Ilustración española. Desentrañar esa posible influencia sobre los diputados gaditanos será el objetivo de este trabajo; proponiendo incluso una conclusión más radical: la hipótesis acerca de que precisamente el agotamiento de un primer pensamiento liberal (el de la Escuela de Salamanca) sería lo que explique la postración y el retraso de España en las postrimerías del Antiguo Régimen.

\footnotetext{
${ }^{1}$ Una versión preliminar de este trabajo fue presentada como ponencia en el III Simposio La razón jurídica: Bicentenario de 1808, organizado por el Grupo de Estudios Lógico-Jurídicos del CSIC (Madrid, 17 y 18 de abril de 2008).

2 Baciero (2003).
} 
Articulo mi exposición en torno a tres apartados: una visión introductoria sobre la doctrina de la Escuela de Salamanca y su importancia en la historia de las ideas políticas; veremos a continuación algunos antecedentes antiguos y medievales, deteniéndonos especialmente en los autores salmantinos de los siglos XVI y XVII: Francisco de Vitoria, Juan Roa Dávila, Francisco Suárez o Juan de Mariana; para terminar con unas hipótesis sobre su posible influencia en el constitucionalismo gaditano de 1812 con tres nombres como Jovellanos, Argüelles y Martínez Marina.

\section{I.}

\section{LA ESCUELA DE SALAMANCA EN LA HISTORIA DEL PENSAMIENTO POLÍTICO}

En los primeros años del siglo XX, los trabajos del profesor norteamericano James Brown Scott (Universidades de Columbia y Georgetown) pusieron de relieve la importancia del pensamiento de Francisco de Vitoria y sus discípulos en la génesis del moderno Derecho Internacional. Esta tesis vio crecer su influencia al terminar la Primera Guerra Mundial, en un ambiente académico preocupado por los fundamentos jurídicos relacionados con la convivencia entre los pueblos. Años después, en la España posterior a su Guerra Civil, esta teoría alcanzó especial difusión en torno al concepto de Escuela de Salamanca como núcleo difusor de las ideas tardo-escolásticas que enseñaron en aquella universidad española Vitoria y sus discípulos o sucesores importantes como Soto, Azpilcueta, Vázquez de Menchaca, Covarrubias, Láinez, Molina, Suárez, y un largo etcétera de maestros universitarios, juristas o filósofos.

En 1952 se incorpora esta línea argumental al campo del pensamiento económico a partir de la obra seminal de M. GriceHutchinson The School of Salamanca; idea que ya había sido antes considerada por J. Schumpeter, aunque no vería la luz hasta la edición en 1954 de su monumental History of Economic Analysis. En ambos casos se plantea una hipótesis sobre si gran parte de los fundamentos de la teoría económica, que posteriormente 
desarrollarían Adam Smith y demás autores «clásicos», ya estaban implícitos en los tratados de aquellos Doctores de Salamanca: tanto en cuestiones particulares sobre cambios e interés, monopolios, impuestos, precios y dinero, etc., como en aspectos más fundamentales como la teoría del valor, la morfología del mercado o los derechos de propiedad.

Un último paso, más reciente pero no por ello menos interesante, ha llevado a estudiar cómo ese pensamiento económico y jurídico, no se extinguió con la decadencia española de finales del XVII. Sino que traspasó las fronteras de la Monarquía Católica a través de los llamados filósofos del Derecho Natural (sobre todo, Hugo Grocio [1583-1645] y Pufendorf), quienes a su vez sirvieron de correa de transmisión para que algunos de los conceptos referidos se recibieran en el ambiente universitario de la Ilustración Escocesa ${ }^{3}$. Así, es una evidencia que Francis Hutcheson (1672-1753), el maestro de Adam Smith en Glasgow, conocía y utilizaba los textos iusnaturalistas de Grocio. Cosa que también es perfectamente verificable en las obras de su discípulo.

Pues bien, nuestra proposición actual — de forma sucintaes que igualmente podemos rastrear en esa transmisión muchas ideas sobre pensamiento político que posteriormente desarrollarían los fundadores del liberalismo clásico. Aquí es preciso recordar la importancia de algunos tratados escolásticos bien conocidos en la Europa Moderna, como fueron las Relecciones De Indis o De potestate civili, de Francisco de Vitoria; la Defensio Fidei (especialmente sus libros III, Principatus Politicus, y VI, De Iuramento Fidelitatis) de Francisco Suárez, y el De Rege et Regis Institutione, de Juan de Mariana. En su lectura se pueden reconocer, como expresaba con acertada maestría el prof. Lucas Beltrán, «las formas de vida social que hoy llamamos liberales: un mundo pacífico, en el cual la propiedad privada respetada, la libertad económica, la democracia política y la moneda sana hacen la vida de todos más agradable» ${ }^{4}$.

\footnotetext{
${ }^{3}$ Con este objetivo presenté recientemente una Tesis Doctoral en la Facultad de Economía de la UCM titulada «La Escuela de Salamanca, Hugo Grocio y el liberalismo económico en Gran Bretaña» (2004).

${ }^{4}$ Así lo escribe en su Introducción al Tratado y discurso sobre la moneda de vellón, de Juan de Mariana (1987), p. 22.
} 
Como ha escrito en numerosos trabajos el prof. Luciano Pereña, el origen de estas disquisiciones se remonta a la enseñanza de Francisco de Vitoria en su Cátedra de Salamanca, a propósito de las consultas de la Corona sobre los fundamentos de la Conquista y gobernación de las Indias (la famosa Duda Indiana), o también sobre las controversias respecto al tratamiento y consideración de los naturales: «El análisis de la obediencia y sumisión que debían los indios al Emperador, les obligaba a definir con exactitud los términos y límites de la libertad política que reiteradamente culminaba en el concepto de democracia como poder del pueblo para el pueblo» ${ }^{5}$.

Dedicaremos el siguiente epígrafe de nuestro estudio a comentar algunos aspectos de esas avanzadas ideas escolásticas sobre el origen democrático del poder político.

\section{II. \\ EL PENSAMIENTO POLÍTICO DESDE ARISTÓTELES A FRANCISCO SUÁREZ}

El marco conceptual en el que soportamos nuestra argumentación tiene que ver con la noción de Iusnaturalismo o Derecho Natural: sin entrar a fondo en esta materia, la idea básica es la creencia en un orden natural que debe inspirar todo el actuar humano. Del mismo modo que existe una armonía en la Naturaleza, con reglas universalmente válidas para sus respectivos campos de influencia, sería posible determinar también unas leyes universales que rigen las acciones humanas. Este típico presupuesto escolástico descansa en una tradición filosófica que llegaría hasta Aristóteles, sin pasar por alto el pensamiento estoico de Cicerón.

En el caso de los hombres, podemos suponer la existencia de un orden natural en las actividades humanas, que es el resultado de su acción, pero no de su designio ${ }^{6}$. Estas normas configurarían

\footnotetext{
${ }^{5}$ L. Pereña (1984), p. 311.

6 Será Hayek quien generalice esta expresión, copiada del maestro de Adam Smith, Ferguson, pero que en realidad puede remontarse a los textos del jesuita Luis de Molina, como demuestra el prof. Manuel Moreira (1992).
} 
tanto el ordenamiento político como el económico ${ }^{7}$. En lo que se refiere al primero, la repercusión de todo ese iusnaturalismo escolástico deviene en la defensa de un orden político natural, en el que la autoridad descansa democráticamente en el pueblo. Y los frutos más conocidos de tales premisas serían la defensa del tiranicidio o la justificación de la Independencia americana.

Sin embargo, no es demasiado frecuente encontrar en nuestros días alguna referencia a esta argumentación, bien extensa a lo largo de los siglos pasados. En los manuales al uso suele repetirse que la historia del Pensamiento Político (moderno) arranca con la Ilustración y los fundamentos teóricos de la Revolución Francesa. Siendo que, insistimos en ello, la Teoría del Poder es una viejísima cuestión que ya Aristóteles analizó magistralmente, que fue después mejor desarrollada por la jurisprudencia romana, el pensamiento cristiano antiguo y medieval, hasta llegar a una interesante culminación en el siglo XVII para en seguida caer casi en el olvido.

\section{Desde Aristóteles a la Edad Media}

Para no alargar demasiado estos primeros epígrafes, me limitaré a glosar brevemente algunas citas fundamentales. En el caso del Filósofo, su teoría política descansa en un principio de legalidad:

«Son las leyes bien establecidas las que deben tener la soberanía» (Política, libro III, cap. 11).

7 Respecto al ámbito económico, los modernos estudios sobre la Escolástica Hispana reconocen con bastante unanimidad los avances de los Maestros de Salamanca en este sentido: su concepción semi-analítica de una "economía de mercado» en la que los precios se fijan por la libre concurrencia (communis aestimatio) entre compradores y vendedores. En sus tratados sobre la Justicia coincidían en afirmar que la situación moralmente más correcta es aquella que resulta del entendimiento espontáneo entre los agentes. Esta tesis general también afectaría a otras cuestiones económicas, como las tasas, los tipos de interés, los salarios, el comercio libre, la propiedad privada o los impuestos. Resultando en una Teoría Subjetiva del valor económico. 
De manera que en muy pocas palabras quedó perfectamente establecido que el fundamento de la autoridad es el cumplimiento de las leyes. Como lo explicaría Tomás de Aquino bastante tiempo después:

«El consentimiento de todo el pueblo, expresado por una costumbre, vale más en lo que toca a la práctica de una cosa que la autoridad del soberano, que tiene facultad de dictar leyes solo en cuanto representante de la multitud. Por eso, aunque las personas particulares no pueden instituir leyes, la totalidad del pueblo sí puede instituirlas» (Summa Theologica, I-II, q. 96, a. 3$) .8$

Matizando, además, en su análisis sobre Las Leyes, que éstas deben orientarse hacia un fin común para la sociedad:

«Toda ley se ordena al bien común de los hombres, y de esta ordenación recibe su fuerza y su carácter de verdadera ley; en la medida en que se aparta de esta finalidad, pierde su fuerza obligatoria» (Summa Theologica, I-II, q. 96, a. 6).

Así pues, el Príncipe no solamente lo es por este traspaso de legalidad; sino que todo su actuar debe quedar sujeto al respeto de la ley:

«Por eso, ante el juicio de Dios, el príncipe no está exento de la ley por lo que toca a su fuerza directiva, y debe cumplirla voluntariamente, no por coacción» (Summa Theologica, I-II, q. 96, a. 5).

8 Aquí traigo a colación el texto de las Decretales que citaba al comienzo de este trabajo, que en realidad tiene un origen bastante anterior (el Código de Justiniano), y cuya interpretación fue pasando del Derecho Civil romano a las disputas conciliaristas medievales, para ser citado finalmente por la escolástica tardía como argumento de filosofía política acerca de la participación del pueblo en el gobierno. Ver a este respecto López de Goicoechea (1999). 


\section{Francisco de Vitoria y la Escuela de Salamanca}

Es claro que no podemos trasladar sin más los postulados del constitucionalismo moderno hasta la época de la España Moderna; pero sí su fundamento filosófico. Que de una manera incipiente lo encontramos recogido en la obra del maestro Francisco de Vitoria, introductor en la Universidad de Salamanca de una nueva forma de teología basada precisamente en la Summa del Aquinate. Es por ello que, evidentemente, su reflexión sobre la autoridad, el poder y la ley (como fundamento de ambas) descansaría en los escritos de santo Tomás que explicaba en sus lecciones y Relecciones.

Como veremos en seguida, los textos de Vitoria dieron pie a una abundante producción bibliográfica a lo largo de casi un siglo. Y con distintas posiciones sobre cuál sea ese fundamento del poder: a veces enfatizando más su carácter popular o democrático, o bien destacando la defensa de una monarquía absoluta como mejor forma de gobierno. Pero lo cierto es que la referencia a Vitoria es unánime, tanto en sus discípulos y seguidores salmantinos, como en la escuela jesuita del XVII. Recordaremos primero algunos textos más conocidos, para después ofrecer algunas conclusiones valorativas.

Las citas más frecuentes provienen del De postestate civili, una temprana Relección universitaria (1528) en defensa de la Monarquía Católica del Emperador Carlos V, escrita en la cercanía a las revueltas de los Comuneros y a la rebelión civil y religiosa de los Príncipes alemanes seguidores de Lutero. De manera que el siguiente párrafo podría ubicar a Vitoria como un claro defensor del absolutismo de derecho divino:

«La monarquía o potestad regia, no solo es justa y legítima, sino que los reyes tienen su poder del derecho divino natural, y no de la república, o mejor, de los hombres» (De potestate civili, p. 8).

Pero se trata de una afirmación más compleja de lo que pareciera, ya que está indicándonos de forma indirecta que la autoridad civil no descansaba en el papado, sino que tenía su propia justificación secular y democrática pero de origen divino: 
«Por constitución, pues, de Dios tiene la república este poder. Y la causa material en la que dicho poder reside por derecho natural y divino es la misma república, a la que compete gobernarse a sí misma, y administrar y dirigir al bien común todos sus poderes» (De potestate civili, p. 7).

Al mismo tiempo, esa primera conclusión aparece también matizada por una muy interesante disquisición sobre lo que sea la «auctoritas» del gobernante, o ejercicio del poder, frente a la «potestas», fundamento ontológico de aquella, que reside en la sociedad:

«Porque aunque el rey sea constituido por la misma república (ya que ella crea al rey), no transfiere al rey la potestad, sino la propia autoridad; ni existen dos potestades, una del rey y otra de la comunidad» (De potestate civili, p. 10).

Unos cuantos años después (1539), al reflexionar de nuevo acerca del gobierno sobre los indios, las guerras americanas y los Justos Títulos de propiedad sobre aquellas tierras, Vitoria va a perfilar mucho mejor este carácter democrático del poder y su transmisión al príncipe, asegurando que todo el poder del rey le viene por elección de la república, a la que representa (De iure belli, pp. 39 y 80).

$Y$ todo este argumentario, que dejaremos aquí, descansa en una premisa que también nos lleva a Aristóteles: el carácter natural del poder, ya que se fundamenta en una condición innata de la familia humana, la sociabilidad:

«Por lo cual Aristóteles, en el libro primero de sus Políticos, demuestra que el hombre es naturalmente civil y social...

Está pues, muy claro, que la fuente y origen de las ciudades y de las repúblicas no fue una invención de los hombres, ni se ha de considerar como algo artificial, sino como algo que procede de la naturaleza misma, que para defensa y conservación sugirió este modo de vivir social a los mortales» (De potestate civili, p. 5).

Después del magisterio de Francisco de Vitoria, y a partir de sus propios comentarios a la Summa de Santo Tomás, varios de sus 
discípulos van a continuar con esta tradición española del «gobierno limitado», con palabras del prof. Dalmacio Negro9. Nos referimos a Martín de Azpilcueta, Domingo de Soto, Diego de Covarrubias o Fernando Vázquez de Menchaca, aunque en esta ocasión no vamos a detenernos a citar sus obras; excepto una referencia al menos conocido Juan Roa Dávila. Su tratado De regnorum iustitia (1591) fue retirado por la Inquisición, tal vez por ser demasiado adelantado a su tiempo. Con palabras del profesor Pérez Luño:

«La primera cuestión viene resuelta de forma explícita por Roa Dávila cuando señala que es la comunidad política la titular del poder, en virtud de la libertad humana y la concesión divina...

Así, la libertad política aparece como un derecho natural del hombre que se proyecta a la comunidad. La titularidad del poder que reside de forma originaria y exclusiva en Dios, se transmite al pueblo como órgano inmediato de la potestad pública...

La potestad política no reside en ningún individuo o grupo social, sino que se haya en el conjunto de todos aquellos que componen la sociedad» (1992, p. 208).

Pero lo mejor es transcribir aquí unos textos originales del autor:

«El pueblo, territorio o nación, que da su consentimiento a un jefe o rey, o incluso a sus sucesores, al elegirlos como a sus propios gobernantes y a tenor de las condiciones del consentimiento, les confiere el poder de soberanía, libremente acordado y estable...

Los pueblos pueden cambiar sus gobernantes, cualquiera que haya sido el sistema de designación, cuando se presentan nuevos motivos justificados» (Roa Dávila, 1970, pp. 3 y 9).

\section{La Defensio Fidei de Francisco Suárez}

Después de Vitoria y sus discípulos dominicos, llegamos a un tercer eslabón tardoescolástico: la nueva escuela jesuita, ya en

\footnotetext{
9 1984, pp. 25 y ss.
} 
los inicios del siglo XVII, con autores famosos como Lessio, Molina, Juan de Mariana o Francisco Suárez; de los que analizaremos brevemente estos dos últimos.

Y comenzamos con este largo tratado del Doctor Eximio, que fue publicado en 1613 para refutar el famoso Juramento de Jacobo I de Inglaterra. Se propone defender la libertad cristiana frente al absolutismo político (el caso de los católicos perseguidos en Gran Bretaña), al tiempo que es una defensa de la autoridad legítima frente a rebeliones injustificadas (el caso de los protestantes sublevados en los Países Bajos): «Con la tradición medieval, Suárez entendía que la potestad política es otorgada por Dios directamente al pueblo, y por el pueblo a los gobernantes» ${ }^{10}$. Esta postura generó susceptibilidades y alguna incomprensión en España, además de ser condenada públicamente en Oxford (1613) y París (1614).

Pero los vericuetos de la Historia permiten afirmar que: «Dos siglos más tarde, en la revolución francesa y aún en el movimiento de la independencia de los virreinatos españoles en América, las ideas democráticas de Suárez son utilizadas como favorables para el pueblo y contrarias a la nobleza». ${ }^{11}$

Los fundamentos de esta tesis descansan en la naturaleza sociable del ser humano, que ya hemos visto cómo Aristóteles había anticipado y Francisco de Vitoria se ocupó de extender. La sociedad civil es una agrupación de derecho natural, y en la comunidad humana descansan unos derechos y deberes anteriores al Estado: «El derecho natural comunitario entrevisto o descubierto por Suárez es una institución divina preestatal y prepolítica, que sirve de base al derecho positivo en todas sus ramas, lo mismo que la ley natural es el fundamento de todas las leyes positivas... El príncipe es, pues, un mero gestor de la república, obligado a una administración que le confiere el pueblo, pero con la condición de que administre el bien público y nada más. No hay, por tanto, un traspaso de poderes, sino de obligaciones con los correspondientes derechos». ${ }^{12}$

\footnotetext{
10 En su Introducción a F. Suárez, Principatus Politicus, 1965, p. V.

11 Ibíd. nota anterior.

12 Introducción de F. Álvarez a la Defensio Fidei, 1969, pp. CL - CLXXV.
} 
Como consecuencia de ello, la autoridad resulta una especie de «propiedad» de la naturaleza humana. Pero la potestad no existe en los hombres considerados individualmente: primero debe constituirse la comunidad, porque allí es donde descansa la justificación del poder. Por derecho natural, este poder no corresponde a ninguna persona concreta, sino a la sociedad en su conjunto.

El razonamiento finaliza considerando cómo es el traspaso de la autoridad a un individuo concreto. Es posible concebir un sistema democrático, en el que el pueblo ejerza por sí mismo la soberanía. Pero lo más frecuente (no olvidemos que estamos hablando del siglo XVII) es que la comunidad ceda esa potestas a una persona física (o a un conjunto de personas). Esta decisión es de derecho positivo. Y la sujeción a esa persona no descansa en el acto del traspaso (que es revocable), sino en un fundamento religioso (Dios, autoridad suprema). Por otra parte, ni el príncipe ni la comunidad pueden transgredir un orden natural, expresado por las leyes justas.

\section{Juan de Mariana: De rege et regis institutione}

Aunque, en opinión del prof. Lucas Beltrán ${ }^{13}$ este libro de Mariana todavía no recoge las opiniones más avanzadas del jesuita en lo relativo a un «orden liberal» que señalo en la Nota 3 , sin embargo para otros autores sí representa una toma de postura en las disputas sobre el ordenamiento político. Por ejemplo, en su introducción al libro VI de la Defensio Fidei ${ }^{14}$ de Suárez, Luciano Pereña incluye al P. Mariana entre los autores populistas, quienes sostienen que la libertad política radica en la soberanía del pueblo. En ese ideario, España se describe como una monarquía

13 En su artículo «Sobre los orígenes hispánicos de la economía de mercado» (1989), pp. 5-38, explica las diversas interpretaciones que se le ha dado a la obra del padre Mariana (un regalista teocrático, un comunitarista social, un defensor de los pobres ...). Beltrán se inclina a considerar que su pensamiento fue evolucionando hacia esas posturas de defensa de la propiedad privada, el ordenamiento democrático o la transparencia económica a la que estamos haciendo alusión.

${ }^{14}$ De Iuramento Fidelitatis, 1978, pp. 159 y siguientes. 
hereditaria, que incorpora a los ciudadanos a su gobierno a través de las Cortes y los Consejos asesores del Rey. El pueblo cooperaría activamente en esas funciones por imperativo del derecho natural, incluso más que por razones de prudencia política.

El pueblo es soberano, porque siempre es superior al monar$\mathrm{ca}, \mathrm{y}$ tiene derecho a exigirle responsabilidades. Incluso puede despojarle de su principado si peligra gravemente la paz y la justicia. Porque la soberanía popular es inalienable: los súbditos deben obediencia al Rey, pero este queda sujeto a las leyes sancionadas por la República. Con el desarrollo de este argumento, Mariana se hizo famoso al convertirse aparentemente en un defensor del tiranicidio (cuando el asesinato de Enrique IV de Francia; por ello, por ejemplo, su libro fue condenado y quemado en París). Sin embargo, parece que sus intereses se dirigen principalmente a limitar los poderes de la monarquía y a controlar los actos del gobierno. Así, defiende claramente la licitud de atentar contra la vida y despojar del poder al tirano que se apodera del Trono por la fuerza. Pero en el caso de un régimen legítimo por la voluntad de los ciudadanos, en el que su rey degenere en la tiranía, hay que preservar unas garantías constitucionales que eviten la ruina del Estado al tratar de echar a ese dictador. Ello implicaría actuar con toda una serie de cautelas como: valorar con prudencia los límites de la opresión; incorporar un procedimiento participativo (contar con las Cortes) si se destrona al Rey; buscar siempre primero un procedimiento jurídico que pueda llevar al tirano ante un Tribunal que le condene; previamente, sería aconsejable darle oportunidad de rectificar o retractarse, o sea, un llamamiento a la cordura; finalmente, y en el caso de contumacia, reconoce la licitud de recurrir a métodos violentos. La fundamentación de ese derecho de rebeldía de los ciudadanos es la defensa del Estado (Mariana, 1981). ${ }^{15}$

${ }^{15}$ Conviene revisar en relación a todo esto la interesante aportación de F. Carpintero (2003). 
III. INFLUENCIAS ESCOLÁSTICAS EN LAS CORTES DE CÁDIZ

Llegamos por fin a la pregunta fundamental de nuestra investigación: ¿qué había quedado de todo esto al tiempo de la invasión napoleónica y la aventura constitucional de Cádiz? Porque desde sus inicios encontramos una frecuentísima referencia a la rebelión del pueblo español frente a un gobierno ilegítimo impuesto por la fuerza. Lo que, de entrada, se nos antoja un evidente recuerdo de aquellas tesis escolásticas acerca de la soberanía popular. También es cierto que por medio habían ocurrido todos los sucesos de la Revolución Francesa, junto a la difusión del pensamiento ilustrado francés o británico.

Aquí es donde me refería a esa generalizada opinión sobre una más importante influencia francesa o inglesa, que incluso pasa por alto cualquier alusión al pensamiento español ${ }^{16}$. Sin embargo, hay bastantes pistas que nos recuerdan los autores escolásticos referidos. Que sin duda debieron ser leídos por, al menos, la última generación de intelectuales españoles del siglo XVIII: en este sentido nos parece que escribe Jorge Vilches cuando habla repetidas veces de la soberanía delegada en el trono (translatio imperii) ${ }^{17}$ como doctrina que todavía pervivía al tiempo de las Cortes. El repaso de algunos nombres y sus obras, junto a las referencias más inmediatas en el proceso constituyente de Cádiz será el objetivo de este tercer epígrafe.

\section{Jovellanos y la Memoria en defensa de la Junta Central (1810)}

Además de su figura como político ilustrado y ministro de Carlos III y Carlos IV, que no es cuestión de tratar ahora, es de todos conocido el protagonismo de Jovellanos al tiempo de las revueltas de

16 Por ejemplo, me llama la atención el librito de Warren M. Diem, publicado por la Universidad de Navarra: Las fuentes de la Constitución de Cádiz, donde se asegura que «la soberanía del pueblo tiene orígenes russonianos» (p. 385), y cuya principal ocupación es descubrir si la mayor influencia sobre las Cortes la tuvieron las constituciones francesas de 1791 y/o de 1795.

17 En su reciente y muy interesante Liberales de 1808, 2008, pp. 252, 302 ó 310. 
1808. Miembro de la Junta Central, fue el primero que propuso la convocatoria de Cortes en la sesión del 7 de octubre de ese año. Sin embargo, ciertas disputas internas y la ofensiva napoleónica de aquel invierno dejaron en suspenso esta iniciativa, hasta enero de 1810.

Pues bien, la justificación teórica de tal convocatoria aparece explicada en una Memoria en defensa de la Junta Central, de 1810, y completada con otros apéndices y notas en 1811. Se trata de una sagaz e interesante descripción de la situación política en la caótica España de comienzos del XIX. Pero en lo que a nosotros nos toca, quiero destacar algunas consideraciones sobre la soberanía nacional (palabra que aparece archirrepetida) en los textos de Jovellanos, que desde luego tienen mucho que ver con el Artículo III de la Constitución de Cádiz:

«La soberanía reside esencialmente en la Nación, y por lo mismo pertenece a ésta exclusivamente el derecho de establecer sus leyes fundamentales».

¿Qué había escrito Jovellanos? Pues algunas reflexiones que ya nos deben resultar familiares. Primero, «es una verdad infalible que la soberanía pertenece originariamente a toda asociación» (Apéndices a la Memoria, n. II, nota primera). De forma que «el poder de los soberanos de España, aunque amplio y cumplido en todos los atributos y regalías de la soberanía, no es absoluto sino limitado por las leyes en su ejercicio, y allí donde ellas le señalan un límite empiezan, por decirlo así, los derechos de la nación» (Apéndices a la Memoria, n.ํㅡㄴㅡ, 7).

Vemos por tanto que, con otras palabras, y seguramente más cercano al lenguaje de su tiempo, Jovellanos mantuvo esos dos principios básicos del gobierno democrático: que la soberanía descansa en la sociedad; y que las leyes están por encima de cualquier autoridad. Otra cosa será perfilar mejor ese concepto de soberanía, sujeto de varias posibles acepciones, como explica en seguida (copio la cita completa):

«Porque habiendo recibido el hombre de su Criador el poder de dirigir libre e independientemente sus acciones, es claro que no 
puede dejar de existir en la asociación de algunos o muchos hombres el poder que existe en todos y en cada uno de los asociados. Pero es menester confesar que el nombre de soberanía no conviene sino impropiamente a este poder absoluto; porque la palabra soberanía es relativa, y así como supone de una parte autoridad e imperio, supone de otra sumisión y obediencia; por lo cual, nunca se puede decir con rigurosa propiedad que un hombre o un pueblo es soberano de sí mismo.

Otro tanto se podría decir de la soberanía política, si por tal se entiende aquel poder independiente y supremo de dirigir la acción común que una asociación de hombres establece al constituirse en sociedad civil; porque desde entonces la soberanía ya no reside propiamente en los miembros de la asociación, sino en aquel o aquellos agentes que hubiere señalado la Constitución para el ejercicio de aquel poder...

Sin embargo, el lenguaje ordinario de la política da el título de soberano a un pueblo así constituido, y no sin buena razón; porque ... siempre se entenderá que todos dirigen aquella acción, ya inmediatamente o ya por medio de sus representantes; $y$, por tanto, se podrá decir sin repugnancia que se han reservado la soberanía, puesto que en ellos queda virtualmente existente» (Apéndices a la Memoria, n.․ XII, nota primera).

Hasta aquí esa breve referencia a don Gaspar de Jovellanos en lo que nos ha parecido que sigue un viejo argumento escolástico y español sobre la justificación de la soberanía del pueblo.

\section{Martínez Marina y su Carta sobre la antigua costumbre de convocar las Cortes de Castilla (Londres, 1810)}

La Biblioteca Virtual Miguel de Cervantes nos ofrece el facsímil de este interesante documento, editado anónimamente en Londres por el jurista Francisco Martínez Marina a instancias de Jovellanos, poco después de que el viejo ministro ilustrado hubiera redactado a su vez la justificación de la convocatoria a Cortes que acabamos de comentar. 
Al igual que en Jovellanos y en otros muchos discursos políticos posteriores, una grave disyuntiva preocupó a los diputados constituyentes: cómo lograr el engarce jurídico de las nuevas Cortes con toda la vieja legislación castellana, arrancando de las Partidas de Alfonso X. Tampoco veremos aquí esta interesante cuestión, sino que simplemente nos fijaremos - al hilo de su estudio sobre las cortes de Castilla- en las referencias de Martínez Marina a la «soberanía popular» de origen escolástico que podamos destacar. Como por ejemplo:

«...la nación representada en las Cortes siempre se creyó con facultades para intervenir en todos los negocios del reino, y para resolver los casos arduos y las dificultades que no se pudiesen desatar por las leyes establecidas: facultades dimanadas del derecho del hombre en sociedad, de los principios esenciales de nuestra constitución, que se extendía en su origen hasta elegir, y con gravísimas causas deponer los soberanos, y de un pacto tácito entre reyes y vasallos jurado solemnemente por ambas partes» (p. 6. La cursiva es original).

Y lo que ahora es una simple contestación epistolar se convertiría, años más tarde, en un consistente tratado de este jurista (asturiano también, por cierto): los Principios naturales de la moral, de la política y de la legislación (1824; una obra que por las circunstancias políticas de su destierro no llegó a publicarse hasta 1933). Donde expresa opiniones tan claras como:

«El sabio teólogo Francisco de Vitoria, que tanto ha descollado entre los escritores españoles del siglo XVI, establece como un principio indubitable y generalmente recibido que la potestad civil está y reside inmediatamente en toda la república o cuerpo social, verdad que han reconocido, dice, tanto los filósofos como los teólogos. Y añade que la república tiene esta potestad por constitución divina, y que la causa material o sujeto en que reside semejante autoridad por derecho divino es la misma república, a la cual compete gobernarse a sí misma y dirigir todas sus fuerzas y facultades al bien común» (cita aquí algunos textos en latín del De potestate civili)... 
El sabio canonista Martín de Azpilcueta, conocido con el nombre de doctor Navarro, dice que ésta es la recta definición de la autoridad civil: una potestad dada natural e inmediatamente a la comunidad de los mortales para gobernarse en las cosas naturales por los principios de la razón...

Y dejadas estas cosas, dice con cierto género de entusiasmo: "yo no puedo olvidarme ciertamente de aquel día feliz del año 1528 en que sostuve y defendí públicamente y con grande aplauso, en un numeroso concurso de sabios y profesores de la universidad de Salamanca, las máximas de Jacobo Almain, a saber, que el reino no es del rey, sino de la comunidad y que la misma potestad regia es por derecho natural de la comunidad misma y no del rey, y que por esta razón no puede absolutamente la comunidad abdicarla» (Martínez Marina, 1993, pp. 61-62).

De manera que, aunque reconocido en su época, sin embargo se nos antoja muy escasa la atención que se le suele prestar en la actualidad, y particularmente su vinculación con el pensamiento político de la Escuela de Salamanca, como acabamos de ver en sus textos. ${ }^{18}$

Pero volviendo a los tiempos de Cádiz, Martínez Marina es recordado también por su Discurso sobre el origen de la monarquía y la naturaleza del gobierno español (1813), que publicó ese mismo año también como Prólogo a su más famosa Teoría de las Cortes (1813). Aquí podemos encontrar, en cuanto a su pensamiento sobre el gobierno, la doctrina del translatio imperii que ya hemos comentado, por la que el pueblo transfiere libremente el poder político a la persona o personas que han de ejercerlo, pero siempre conservando un poder de inspección y de control sobre el Príncipe, a fin de que no traspasara sus límites degenerando en tiranía ${ }^{19}$. Situación que, como estamos repitiendo, los españoles

18 «La obra de Martínez Marina precedió a todo el proceso constitucional y fue citada con elogio por Jovellanos... Los puentes doctrinales entre esta tradición del pasado y las ideas del presente se construyeron con interpretaciones de teorías escolásticas». Suárez (19, p. 311).

19 Aquí cita a Mariana y su famoso «populus supra Principem; Princeps infra legem». 
(y americanos) de 1808 eran plenamente conscientes de que acababa de producirse en su país con la Invasión francesa, y que requería una respuesta de rechazo según los principios más básicos del Derecho. Este razonamiento terminaba apelando a la inteligencia y valor de los pueblos para oponerse a la usurpación francesa con unas palabras que, vistas ahora, nos parecen perfectamente aplicables a la casi inmediata deriva absolutista del Deseado Fernando VII. Un texto tal vez premonitorio, y con una muy interesante reflexión final sobre la patria y la libertad:

\begin{abstract}
«Los pueblos imbéciles y estúpidos que no tuvieron la suficiente energía para conservar su dignidad y defender sus prerrogativas ni para tomar medidas de precaución contra las demasías de los Reyes, ni para oponerse en tiempo oportuno a sus empresas tiránicas, perdieron la libertad civil y política, se familiarizaron con la opresión hasta amar sus cadenas, dexaron de ser naciones» (p. 115). ${ }^{20}$
\end{abstract}

Sobre Francisco Martínez Marina podríamos escribir largamente, y recordar también cómo ha sido citado en algunos textos que estamos comentando aquí (Vilches, 2008, págs. 176-177 o Pérez Luño, 1992, págs. 49 y ss.). Sin olvidar por ello las excelentes reediciones de sus obras que publica el Centro de Estudios Constitucionales o la colección Clásicos Asturianos del Pensamiento Político. ${ }^{21}$

\title{
3. Agustín de Argüelles y su Discurso preliminar a la Constitución de 1812
}

Por buscar una tercera referencia política a nuestra «soberanía popular» de origen escolástico, termino con uno de los oradores más famosos del tiempo de las Cortes (el divino se le llamó). Personaje culto y liberal, Argüelles se había formado en una

20 Martínez Marina (1988). Conviene leer despacio el estudio introductorio de José A. Maravall.

${ }^{21}$ Quiero señalar, por último, un texto menos conocido de Jaime Alberti (1980). 
retórica que todavía conservaba lo mejor de nuestra tradición universitaria, y al mismo tiempo conocía bien a todos los autores que venimos citando en este trabajo: desde Aristóteles y santo Tomás a los maestros de Salamanca ${ }^{22}$. No es de extrañar, por tanto, que Jovellanos le citara con respeto:

«Hay seguramente en las Cortes hombres de instrucción y de juicio, entre los cuales descuella, según dicen, nuestro Agustín Argüelles, quantum lenta solent inter viburna cupressi; pero sé que hay otros cuyos principios políticos son bebidos sin reflexión en Juan Jacobo, Mably, Locke, Milton y otros teoréticos que no han hecho más que delirar en política» (Carta de Jovellanos a lord Holland; Muros, 5 de diciembre de 1810).

Don Agustín de Argüelles (nacido en 1776) pertenece a una generación claramente posterior a la del ilustrado Jovellanos (1744) o el clérigo Martínez Marina (1754). Comparte con ambos su origen asturiano, y una buena formación en la Universidad de Oviedo en la que ingresó con solo doce años. De manera que, como sus predecesores, Argüelles adquirió una sólida cultura jurídica que se puso de manifiesto en los famosos Discursos que pronunciaría en las tribunas de las Cortes de Cádiz. Como quiera que nuestro estudio toca ya a su fin, y además Argüelles ofrece una interesante biografía que casi alcanza hasta mediados del siglo XIX, tan solo vamos a esbozar ahora algunas consideraciones breves en torno a esos conceptos de filosofía política de estamos recordando. Para ello, conviene revisar la edición de sus Discur$\operatorname{sos}^{23}$, y en particular su Discurso preliminar a la Constitución de $1812 .{ }^{24}$

22 Así, Rodrigo Fernández de Carvajal escribe: «Otra tercera perspectiva, bien dibujada por Sánchez Agesta, es la actitud positiva y estimatoria de muchos de los hombres de nuestra Ilustración, sobre todo eruditos e historiadores, hacia la tradición política medieval y hacia el 'populismo' de la segunda escolástica: Vitoria, Martín de Azpilcueta, Molina, Suárez, Mariana»; (1982), pp. 289-297.

${ }^{23}$ Edición de F. Tomás y Valiente para los Clásicos Asturianos del Pensamiento Político, 1995.

24 Edición de Luis Sánchez Agesta en el Centro de Estudios Constitucionales, 1989. 
Vuelvo a señalar aquí el debate acerca de los orígenes históricos de la Monarquía española y sus leyes para encajarlas en la nueva Carta; la discusión acerca del pactismo medieval, o el ya referido recelo de Jovellanos hacia cualquier pensamiento del exterior. Argüelles escribió algunas consideraciones similares, que nos permiten calibrar esa prudencia intelectual de los diputados de Cádiz a la hora de recibir la filosofía política imperante en Europa:

«Yo procuraré tranquilizar a cualquiera que recele de esta cuestión con razones y autoridades sacadas, no de Monitores franceses, no de escritores extranjeros ni filósofos novadores, sino de las fuentes puras de la historia de España, de los venerables y santos monumentos de nuestra antigua libertad en independencia» (Discursos I.6 «Sobre la abolición de los señoríos»; p. 87).

Y de la misma forma encontramos algunas, ya ciertamente escasas, referencias a los autores escolásticos citados atrás: como su recuerdo de «los Mariana» en el Discurso preliminar (p. 70), con un lenguaje que nos debe resultar familiar en lo que toca al «principio innegable que la autoridad soberana está originaria y esencialmente radicada en la nación»; o a «la soberanía de la nación, opuesta al reparto patrimonial de Napoleón» y a las «limitaciones en el ejercicio de la autoridad real» (pp. 78-80).

El balance final de nuestro trabajo, que sirve también como última mirada al pensamiento de Argüelles, lo tomaré de la introducción de Sánchez Agesta al Discurso preliminar que venimos comentando. Porque me ha parecido muy acertado su reconocimiento de la pervivencia, en Cádiz, de «una ingente doctrina, por llamarle así, 'populista', en nuestro pensamiento clásico, en Vitoria, en Navarro [Azpilcueta], en Molina, en Suárez, en Mariana...». Doctrina que venía siendo recogida y «desempolvada» por el gran historiador que fue Martínez Marina; y que produjo la paradoja de «este curioso manifiesto de una revolución que pretende restaurar una tradición; o de una revolución tradicional que se apoya en la memoria de una tradición revolucionaria» (1989, p. 41). Mi conclusión e hipótesis final es que, en Cádiz, los liberales sostuvieron unas tesis del pensamiento 
político tradicional que, lamentablemente, los realistas no fueron capaces de asumir. ${ }^{25}$

\section{REFERENCIAS BIBLIOGRÁFICAS}

Alberti, J. (1980). Martínez Marina, derecho y política, Oviedo. Aquino, T. DE (1959). Suma de teología, Madrid, BAC. Aristóteles (1997). Política, Madrid, Centro de Estudios Políticos y Constitucionales.

ArgüELles, A. DE (1989). Discurso preliminar a la Constitución de 1812, Madrid, Centro de Estudios Constitucionales.

- (1995). Discursos, Oviedo, Clásicos Asturianos del Pensamiento Político.

BACIERO, F. (2003). «El De Legibus de Suárez y Locke», Revista Española de Filosofía Medieval 10, pp. 387-393.

BELTRÁN, L. (1989). «Sobre los orígenes hispánicos de la economía de mercado", Cuadernos del pensamiento liberal 10, pp. 5-38.

\footnotetext{
${ }^{25}$ No es posible explicar esta afirmación sin analizar a fondo toda la compleja discusión política generada en Cádiz, y de la que simplemente mostraré como botón esta larga cita: «Dos son los principios claves en la Constitución del 12: la soberanía nacional y la división de poderes. En realidad, ambos principios ya habían sido proclamados a través del Decreto I de 24 de septiembre de 1810, pero su inclusión en la Constitución gaditana implicó arduos debates en los que, finalmente, lograron imponerse los liberales. Por lo que se refiere a la soberanía nacional, recogida en el artículo 3 del texto, la discusión más importante tuvo lugar entre realistas y liberales a la hora de interpretar el adverbio «esencialmente» («La soberanía reside esencialmente en la Nación...») y el inciso final del artículo («por lo mismo, pertenece a ésta exclusivamente el derecho de establecer sus leyes fundamentales»). Los realistas consideraban que, tal y como se redactaba el artículo, la Nación podía cambiar las antiguas leyes del Reino sin contar con la voluntad del Rey; algo impensable para ellos, que sostenían que las Leyes Fundamentales eran un pacto bilateral que no podía ser anulado unilateralmente por ninguna de las partes. Para los realistas, la Nación sólo había «reasumido» la soberanía como consecuencia de la vacancia del Trono, pero ello no le habilitaba a hacer tabula rasa de las antiguas Leyes Fundamentales. Los liberales, sin embargo, consideraban que la Nación era soberana en sí misma, al margen de la presencia o ausencia del Rey; por lo tanto, su poder soberano la convertía en titular del poder constituyente, al que la historia no podía limitar». Contexto histórico de la Constitución española de 1812, por Marta Friera Álvarez e Ignacio Fernández Sarasola (Universidad de Oviedo). http://www.cervantesvirtual.com/portal/1812/contexto2.shtml
} 
Carpintero, F. (2003). «Los escolásticos españoles en los inicios del liberalismo político y jurídico», Revista de Estudios Histórico-Jurídicos XXV, pp. 341-373.

Diem, W.M. (1967). Las fuentes de la Constitución de Cádiz, Pamplona, Universidad de Navarra.

Fernández de Carvajal, R. (1982). «En torno al Discurso preliminar de Argüelles», Revista Española de Derecho Constitucional 5, pp. 289-297.

Jovellanos, M. DE (1975). Memoria en defensa de la Junta Central, Madrid, Espasa Calpe.

LÓPEZ DE GoicoecheA, J. (1999). «La fórmula romano medieval Quod omnes tangit en el pensamiento político español de los siglos XVI-XVII», Cuadernos salmantinos de filosofía 26, pp. 115-132.

Negro, D. (1984). El liberalismo en España, Madrid, Unión Editorial.

MARIANA, J. DE (1981). De rege et regis institutione, Madrid, Centro de Estudios Constitucionales.

- (1987). Tratado y discurso sobre la moneda de vellón, Madrid, IEF.

MARTíneZ, F. (1988). Discurso sobre el origen de la monarquía, Madrid, Centro de Estudios Constitucionales.

- (1993). Principios naturales de la moral, de la política y de la legislación, Oviedo, Clásicos Asturianos del Pensamiento Económico.

Moreira, M. (1992). «Luis de Molina e as origens ibericas da economia de mercado", Actas do Encontro Iberico sobre Historia do Pensamento Económico, Lisboa, pp. 41-62.

Pereña, L. (1984). «La Escuela de Salamanca y la Duda Indiana», en La ética de la conquista de América, Madrid, CSIC, pp. 291-312.

Pérez, A. (1992). La polémica del Nuevo Mundo, Madrid, Trotta.

RoA, J. DE (1970). De regnorum iustitia, Madrid, CSIC.

SuÁrez, F. (1987). «Las Cortes de Cádiz», Historia General de España y América, t. XII, Madrid, Rialp.

SuÁrez, F. (1965). Principatus Politicus, Madrid, CSIC.

- (1969). Defensio Fidei, Madrid, IEP.

- (1978). De Iuramento Fidelitatis, Madrid, CSIC.

Vilches, J. (2008). Liberales de 1808, Madrid, Gota a Gota.

Vitoria, F. DE (1974). Relecciones, México, Porrua. 